\title{
Petunjuk Sistem Perlapisan Bumi Dangkal melalui Analisis Seismogram
}

\author{
Bagus Jaya Santosa* \\ Jurusan Fisika-FMIPA, Institut Teknologi Sepuluh Nopember \\ Kampus ITS Sukolilo, Surabaya 61111
}

\begin{abstract}
Intisari
Dalam penelitian ini telah diperbandingkan seismogram observasi dengan kurva waktu tempuh dari sebuah gempa dalam komponen ruang 3 dimensi. Data seismogram berasal dari Hokaido, Jepang yang terjadi pada tanggal 8 Oktober 1997, direkam oleh stasiun pengamat yang terletak di HIA, Propinsi Neimenggu, China. Untuk mengidentifikasikan fase gelombang dalam seismogram digunakan kurva travel time, yang dihitung dengan program TTIMES, yang didasarkan pada sebuah sebuah model bumi elastik, simetri radial dan isotrop, yaitu model bumi IASPEI91. Pada model bumi ini, hingga kedalaman $100 \mathrm{~km}$, bumi diperkirakan mempunyai dua antarmuka, yaitu antarmuka pada kedalaman $20 \mathrm{~km}$ antara kulit bumi atas dan bawah, dan pada kedalaman 35 $\mathrm{km}$, dikenal sebagai antarmuka Mohorivicic, sebagai batas antara mantel bumi dengan kulit bumi. Antarmuka kedua bertindak sebagai reflektor gelombang yang sangat kuat. Penelitian ini memberikan petunjuk, bagaimana sebenarnya sistem perlapisan tanah dangkal pada model bumi elastik. Dijumpai diskrepansi yang nyata pada berbagai fase gelombang, yang tidak tertera, baik dalam segmen waktu gelombang ruang langsung dan terpantul, dan segmen waktu gelombang dalam, dimana gelombang diskrepansi tersebut datang pada jendela waktu diantaranya. Ini menunjukkan, bahwa model bumi harus dilengkapi dengan antarmuka pemantul-pemantul dangkal. sistem perlapisan yang lebih halus/tipis juga dinyatakan oleh adanya gejala difraksi pada segmen waktu gelombang langsung. Meskipun jenis gelombang yang digunakan dalam penelitian ini adalah Long Period, namun terbukti dapat menunjukkan resolusi yang sangat peka.
\end{abstract}

KATA KUNCI: seismogram, model bumi, perlapisan dangkal

\section{PENDAHULUAN}

Sebuah gempa yang besar menghasilkan gerakan tanah yang dapat dicatat di hampir seluruh permukaan bumi. Melalui seismometer yang sensitif di stasiun penerima, gerakan tanah akibat gempa tersebut direkam dan disajikan kembali sebagai seismogram. Seismogram tersusun atas fasefase gelombang yang kompleks, berasal dari refleksi/refraksi yang terjadi di dalam bumi, akibat adanya perbedaan parameter elastik pada sistem perlapisan model bumi, disebut antarmuka, sepanjang perambatan gelombang dalam medium bumi dari sumber gempa hingga stasiun penerima.

Beberapa fase gelombang utama dapat dicatat waktu-waktu tiba fase gelombang utama. Melalui pengamatan atas selisih waktu tiba gelombang-gelombang utama pada serangkaian seismometer yang melingkupi daerah sumber gempa, kemudian ditentukan kedudukan episenter gempa.

Pasangan data waktu tempuh sumber-gempa - penerima atas berbagai fase gelombang dan banyak gempa bumi, dalam waktu 10 tahun dapat mencatat data waktu tempuh gelombang dalam jumlah hingga jutaan. Data ini dimanfaatkan untuk menurunkan struktur model bumi, lihat IASPEI91 [1] dan SPREM [2].

Sebuah pengandaian model bumi diperlukan untuk menghitung seismogram sintetik atas besaran fisis yang terukur, yaitu

*E-MAIL: bjs@physics.its.ac.id waktu tempuh gelombang, polaritas gelombang dan tinggi amplitudonya.

Data seismogram juga dapat digunakan untuk menurunkan sebuah model bumi. Ada 3 metode yang digunakan untuk menurunkan model bumi, yaitu analisa onset time fase-fase gelombang ruang (body wave), analisa dispersi pada gelombang permukaan dan perbandingan seismogram dalam kawasan waktu. Dua metoda disebut pertama hanya mengevaluasi sedikit informasi tertentu dalam sebuah deret waktu seismogram, sedangkan metoda ketiga adalah yang terbaik, karena akan diperbandingkan keseluruhan informasi yang terkandung dalam seismogram [3].

Model bumi IASPEI-1991 diturunkan dari kompilasi atas jutaan waktu tempuh gelombang dari ribuan pasangan sumber gempa-stasiun pencatat, dengan sedikit informasi tambahan dari analisa dispersi gelombang permukaan, untuk melengkapi parameter elastik dari model bumi yang dihasilkan.

Jika sebuah gempa bumi terjadi, Lembaga Seismologi di Negara setempat segera mengumumkan letak hiposenter dan kekuatan gempa tersebut, misal BMKG. Beberapa bulan kemudian solusi CMT yang memuat keterangan mengenai saat, lokasi dan mekanisme bidang-bidang patahan gempa diumumkan oleh Lembaga Seismologi Internasional.

Dalam penelitian ini, seismogram riil dari gempa Hokaido, Jepang 8 Oktober 1997, dibandingkan dengan waktu tiba fase-fase gelombang utama, yang dihitung dengan program TTIMES [4] pada satu stasiun pengamatan, yaitu di HIA, Prop. Neimenggu, China, dimana pencatat seismogram diambil di daerah sekitar sumber gempa pada jarak episentral di 


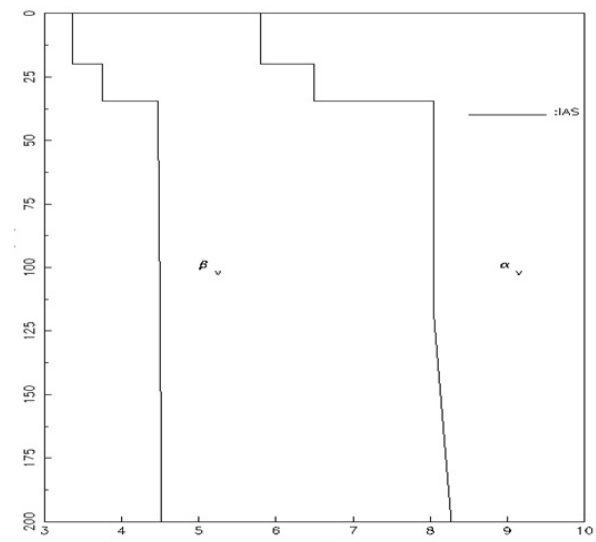

Gambar 1: Penampang model bumi dari model bumi standar isotrop, IASPEI91 hingga kedalaman $200 \mathrm{~km}$.

\section{sekitar 200.}

Model bumi global yang sering dijadikan acuan oleh risetriset seismologi lanjutan, yaitu IASPEI91 [1] dapat dilihat pada Gambar 1.

\section{METODOLOGI PENELITIAN}

Data seismogram dapat diperoleh dari beberapa Databank Center (lihat http://dmc.iris.washington.edu), yang datanya dapat diakses melalui halaman Web. Setiap gempa menghasilkan pergerakan tanah, yang oleh sebuah stasiun akan direkam dalam arah ketiga komponen Kartesian (U-S, T-B dan Z, lokal pada kedudukan stasiun penerima). Kedudukan sumber gempa adalah di Hokaido, Jepang dengan koordinat $41,76^{\circ}$ Utara dan $145,44^{\circ}$ Bujur Timur. Untuk memisahkan komponen pergerakan tanah dalam arah transversal dan radial, arah U-S dan T-B lokal di stasiun penerima harus diputar. Langkah yang diambil adalah dengan mendudukkan sumber gempa sebagai Kutub Utara, kemudian kedudukan dan arah stasiun penerima dihitung kembali sesuai dengannya. Stasiun penerima berjarak episentral $18,6^{\circ}$ terhadap horisontal dan melihat kedudukan (azimut) sumber gempa pada arah $238,6^{\circ}$ (arah diambil dari Utara searah dengan jarum jam). Setelah data diputar menurut arah transversal (U-S) dan radial (T-B) dan vertikal $(Z)$, kemudian diperagakan kembali sebagai seismogram riil dalam ketiga komponen.

Pertama dalam penelitian ini harus dijalankan program komputer untuk melaksanakan perhitungan atas waktu tempuh fase-fase gelombang ruang utama, yaitu program TTIMES yang dibuat berdasarkan makalah dari Bulland \& Chapman [4] didapat dari http://orfeus.knmi.nl. Ketika program ini dijalankan, haruslah sebuah model bumi diberikan sebagai input, yaitu model bumi IASPEI91. Sebagai model bumi masukan, data harus mengandung parameter elastik secara lengkap, yaitu meliputi kecepatan penjalaran gelombang kompresi dan shear dari batuan penyusun struktur bumi.

Hipotesa atas penjalaran gelombang dalam medium isotrop menyatakan, bahwa gelombang menjalar dalam bidang planar

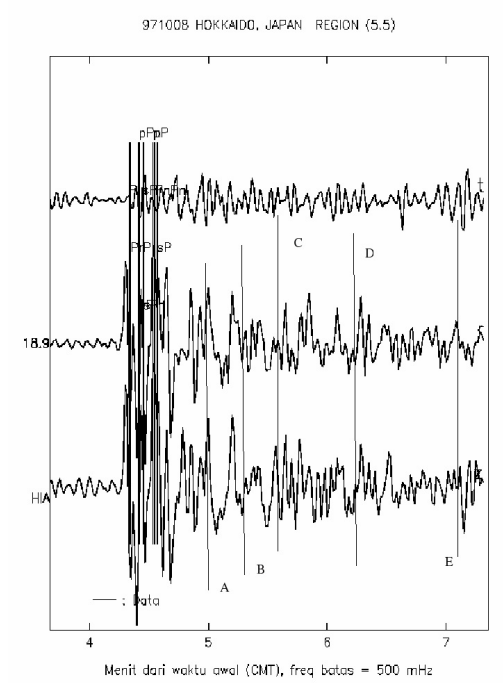

Gambar 2: Perbandingan seismogram dalam kawasan waktu pada jendela waktu untuk fase-fase gelombang kompresi dalam ruang koordinat $\mathrm{z}, \mathrm{r}$ dan $\mathrm{t}$

(XZ) dan yang tegak-lurus terhadap bidang tersebut (Y), dimana bidang vertikal mempunyai arah pada busur lingkaran antar episenter dengan stasiun. Dengan demikian pergerakan tanah dibentuk oleh komponen sferoidal (P-SV) dan gelombang transversal (SH). Oleh karena itu komponen gerakan dalam sistem koodinat Kartesian lokal di penerima harus diputar. Pemutaran pada bidang horisontal, sehingga sistem koordinat lokal di stasiun pengamat diarahkan pada arah busur kecil antara sumber gempa dengan stasiun penerima. Ini untuk mengamati gelombang SH pada komponen tegak-lurus ( $\mathrm{t}$, atau dalam komponen y baru), dan gelombang P-SV ( $\mathrm{r}$ dan z, atau dalam bidang $\mathrm{x}-\mathrm{z}$ baru).

\section{ANALISA DAN PEMBAHASAN}

Dalam penelitian ditampilkan analisa sebuah gempa Hokaido, Jepang 8 Oktober 1997, yang gelombangnya ditangkap oleh sebuah stasiun observasi seismologi HIA di Propinsi Neimenggu, China

Gambar 2 memperlihatkan seismogram dalam tiga komponen dan perbandingan seismogram observasi dengan waktuwaktu tempuh gelombang utama yang dihitung dari model bumi IASPEI91 (dinyatakan sebagai garis vertikal dalam Gambar 2). Sumbu datar menyatakan sumbu waktu setelah terjadinya gempa bumi, sedangkan sumbu vertikal menyatakan amplitudo gelombang datang di stasiun penerima.

Pada jarak episentral sebesar 18,9 derajat, gelombang PnPn menunjukkan gelombang yang menjalar antara sumber gempa hingga penerima melalui antarmuka lapisan kulit bumi atas dengan kulit bumi bawah. Di belakang fase gelombang ini, tidak ada lagi gelombang yang menjalar dekat permukaan, dimana gelombang masih bertindak sebagai gelombang ruang, untuk membedakannya dengan gelombang permukaan. Karena sumber gempa terletak di bawah permukaan bumi, se- 
bagian gelombang merambat ke atas terlebih dahulu, terpantul di permukaan bebas, dan menjalar kemudian hingga stasiun penerima. Paket-paket gelombang $\mathrm{P}, \mathrm{PnPn}, \mathrm{pP}$ semuanya terletak dalam jendela waktu 4,3 hingga 4,8 menit. Sebagian gelombang yang terpancar oleh gempa bumi menjalar ke bawah, ke arah inti bumi, dan kemudian gelombang oleh Batas Inti Bumi (CMB) dipantulkan kembali ke permukaan bumi, gelombang ini dinotasikan dengan $\mathrm{PcP}, \mathrm{PcS}, \mathrm{ScP}$ dan ScS. Fase-fase gelombang ini terletak dalam jendela waktu sekitar 7,9 hingga 8,1 menit.

Ketika gelombang terpantul dan menjalar kembali ke atas, akan menjumpai antarmuka udara bebas. Jika gelombang datang dengan sudut riil, maka gelombang akan nampak sebagai fase gelombang lengkap. Namun dalam gambar 2 kita dapat melihat beberapa kereta fase gelombang, misal pada jendela waktu antara 5,5 hingga 5,8 menit. Ini menunjukkan terjadinya dispersi gelombang, yaitu gelombang menjalar dengan kecepatan fase berbeda pada tiap frekuensinya, misal dalam segmen waktu 5,5 - 6 menit dispersi tersebut dapat diamati, gelombang dengan perioda lebar (frekuensi rendah) menjalar lebih cepat daripada frekuensi tinggi. Dispersi ini berasal dari gelombang pantul yang ketika menjumpai antarmuka udara bebas dengan sudut lebih besar daripada sudut kritis, tertransformasi menjadi gelombang permukaan, dimana dapat diamati dengan gejala disperse, jika model bumi dangkal tersusun atas tanah yang berlapis-lapis [3].

Di dalam kereta gelombang, kita dapat melihat beberapa fase gelombang datang dengan amplitudo yang lebih tinggi dan energi yang kuat, ini berasal dari pemantulan dengan sudut datang riil. Dalam gambar kedatangan fase-fase gelombang yang dinotasikan dengan A,B,C,D dan E menunjukkan kedatangan gelombang-gelombang pantul. Dengan memper- hatikan jendela waktu dari gelombang $\mathrm{P}, \mathrm{pP}, \mathrm{PP}$ yang berada di 4,3 hingga 4,8 menit dan PcP,PcS, ScP yang berada di jendela waktu 7,9 hingga 8,1 menit, jendela waktu gelombang dengan notas A hingga E belum dijelaskan oleh para ahli seismologi. Namun jelas dapat dinyatakan dari gambar ini, bahwa antarmuka-antarmuka yang menjadi pemantul gelombang A hingga E haruslah terletak dangkal.

Seismogram difilter dengan frekuensi pojok $500 \mathrm{mHz}$, atau Nyquist pada $1 \mathrm{~Hz}$, ini menunjukkan bahwa panjang gelombang mempunyai orde yang sama dengan kecepatan penjalaran gelombang, di dekat permukaan, sekitar $4 \mathrm{~km}$. Meskipun panjang gelombang mempunyai nilai yang besar, ia dapat meresolusikan sistem perlapisan bumi dangkal dengan baik.

\section{SIMPULAN}

Penelitian ini memberikan petunjuk, bagaimana sebenarnya sistem perlapisan tanah dangkal pada model bumi elastik. Dijumpai diskrepansi yang nyata pada berbagai fase gelombang, yang tidak tertera, baik sebagai gelombang ruang langsung dan terpantul dan gelombang dalam, dimana gelombang tersebut datang pada jendela waktu diantaranya. Ini menunjukkan, bahwa model bumi harus dilengkapi dengan antarmuka pemantul-pemantul dangkal. sistem perlapisan yang lebih halus/tipis juga dinyatakan oleh adanya gejala difraksi pada segmen waktu gelombang langsung. Meskipun jenis gelombang yang digunakan dalam penelitian ini adalah Long Period, namun terbukti dapat mempunyai resolusi yang sangat peka.
[1] Kennett, B.L.N., Seismological Tables, Research School of Earths Sciences, Australian National University,IASPEI 1991.

[2] Dziewonski, A.M. and Anderson, D.L., Phys. of the Earth and Plan. Int., 25, 297-356 (1981).

[3] Gubbins, D., Seismology and Plate Tectonics (Cambridge University Press, Cambridge, 1990)
[4] Bulland, R. and Chapman, C., Travel time Calculation, BSSA, 73,1271-1302 (1983).

[5] Bagus J.S, Menggugat Kebenaran Model Bumi Berlapis, Majalah IPTEK 2001 